\title{
Erratum to: The anti-proliferative effects of norcantharidin on human HepG2 cells in cell culture
}

\author{
Cheng Chang $\cdot$ Youqing Zhu $\cdot$ Xiaoyan Tang $\cdot$ \\ Wenhui Tao
}

Published online: 28 November 2012

(C) Springer Science+Business Media Dordrecht 2012

\section{Erratum to: Mol Biol Rep (2011) 38:163-169 \\ DOI 10.1007/s11033-010-0090-6}

An acknowledgement has been added to the existing publication:

The Acknowledgements says "The research was supported by the Key Project Fund of the Shanghai Municipal Committee of Agriculture (No. 2009-6-4) and the
Key Project Fund of the Shanghai Municipal Committee of Agriculture (No. 2011-1-8) and International Scientific and Technological Cooperation (2010DFA62320, 11230705900) and National Natural Science Foundation (31071486). The funders had no role in study design, data collection and analysis, decision to publish, or preparation of the manuscript".

Other, "ARTS" in the Table 1 should be "ABTS".

The online version of the original article can be found under doi:10.1007/s11033-010-0090-6.

C. Chang $\cdot$ Y. Zhu $(\bowtie) \cdot$ X. Tang $\cdot$ W. Tao Department of Gastroenterology, Zhongnan Hospital of Wuhan University, East-Lake Road 169, 430071 Wuhan,

Hubei Province, China

e-mail: hubeitcm@sohu.com 